\title{
Development and Validation of RRLC-UV Method for Determination of Chlorogenic Acid in Green Coffee
}

\author{
Lenche Velkoska-Markovska, Mirjana S. Jankulovska*, Biljana Petanovska-Ilievska and \\ Kristijan Hristovski \\ Faculty of Agricultural Sciences and Food, Ss. Cyril and Methodius University, Blvd. Aleksandar Makedonski bb, P. O. Box 297,
1000 Skopje, Republic of Macedonia
}

Received: 14 September 2018; accepted: 26 November 2018

\begin{abstract}
Coffee is one of the most widely consumed beverages in the world. It contains many bioactive compounds, including chlorogenic acid which possesses various biological properties. In this study, in order to determine concentration of chlorogenic acid in green coffee, a reverse-phase rapid resolution liquid chromatography (RP-RRLC) method with diode-array detection (DAD) was developed. Successful separation was achieved on a Poroshell 120 EC-C18 $(50 \mathrm{~mm} \times 3 \mathrm{~mm} ; 2.7 \mu \mathrm{m})$ column using acetonitrile-water with $1 \%$ phosphoric acid $(10: 90, v / v)$ as a mobile phase, at a flow rate of $1 \mathrm{~mL} / \mathrm{min}$, and with UV detection at $325 \mathrm{~nm}$. The identification was made with comparison of the retention time of pure analytical standard with the retention time of chlorogenic acid in the analyzed samples. The developed method was validated using the following parameters: linearity, sensitivity, selectivity, precision, and accuracy. Excellent linearity over the range $12.33-143.50 \mu \mathrm{g} / \mathrm{mL}$ was achieved with $R^{2}$ values greater than 0.99 . The intra-day precision was validated with the $\% R S D$ values, which confirmed that the method for determination of chlorogenic acid was repeatable. The mean recovery rate of the method ranged between $97.87 \%$ and $106.67 \%$ with $\% R S D$ values lower than $1 \%$. The limit of detection and limit of quantification values under the used chromatographic conditions were 0.29 and $0.96 \mathrm{pg}$, respectively. This method was successfully employed for quantitative determination of chlorogenic acid in green coffee samples.
\end{abstract}

Keywords: chlorogenic acid, RP-RRLC, green coffee, extraction, separation, method validation

\section{Introduction}

Coffee is one of the most popular beverages in the world. The popularity of the coffee is due to its unique flavor, making it one of the most desirable and frequently consumed beverages worldwide. It has a strong historical, cultural, social, and economic importance as well [1]. Botanically, coffee belongs to the family Rubiaceae in the genus Coffea. Commercial coffee beverages are made from Coffea arabica or Coffea robusta beans or blends of them, and its quality is strictly related to the chemical composition of the roasted beans, which is affected by the composition of the green beans and postharvesting processing conditions [2]. Typical compounds in coffee, such as caffeine, trigonelline, and chlorogenic acid, are known to influence coffee flavor, acidity, and bitterness [3]. Chlorogenic acid and its derivatives are few of the main phenolic compounds present in coffee [4]. As it is well known, the main characteristic of phenolic compounds is their ability to trap free radicals that cause degenerative diseases [5]. These compounds have antioxidant properties, which play an important role in protecting food, cells, and organs from oxidative degenerative diseases [5]. Diet rich in chlorogenic acid prevents various diseases associated with oxidative stress such as cancer, cardiovascular, aging, and neurodegenerative diseases [6]. Chlorogenic acid has an important influence on the formation of pigments, taste, and flavor of coffee beans, which determines the quality and acceptance of the beverages [6]. According to Farah et al., the concentration of chlorogenic acid has an inverse association with coffee quality, i.e., higher

\footnotetext{
* Author for correspondence: jankulovska@fznh.ukim.edu.mk
}

contents is observed in a lower quality coffee sample [7]. The concentration of chlorogenic acid in raw coffee is much greater than that in the roasted one. This suggests that the degree of roasting affects the concentration of chlorogenic acid, i.e., during roasting, degeneration of chlorogenic acid and its derivatives occur [8]. The content of chlorogenic acid in the coffee beverage depends on the species, the variety, and the processing conditions of the coffee beans [9]. The green coffee contains 5-12 g/100 g chlorogenic acid [7]. Chlorogenic acid is an ester of trans-cinnamic acid, such as caffeic acid, ferulic, and $p$-coumaric acid with (-)-quinic acid.

The literature revels that for quantitative analysis of bioactive compounds such as chlorogenic acid in food and beverages several techniques can be used [10-12]. However, highperformance liquid chromatography (HPLC) remains one of the most common techniques which give accurate results [1, 13-17]. Chlorogenic acid can be determined by HPLC applying different chromatographic conditions. The most frequently used combinations of solvents are as follows: a mixture of methanol and $0.2 \mathrm{~mol} / \mathrm{L}$ acetate buffer $(\mathrm{pH} 3.6)(15: 85, \mathrm{v} / \mathrm{v})$, combination of methanol-water-acetic acid $(19: 81: 1.5, v / v)$, a mixture of aqueous phosphoric acid solution $(0.1 \%)$ and acetonitrile $(90: 10 \mathrm{v} / \mathrm{v})$, and so on. In these investigations, a flow rate of $1.0 \mathrm{~mL} / \mathrm{min}$ or $1.5 \mathrm{~mL} / \mathrm{min}$ was set up with isocratic or gradient elution and UV detection at $300 \mathrm{~nm}[18,19]$. Different stationary phases were used, as well. However, there is a constant need to improve analytical methods for quantitative determination in order to obtain a more accurate, precise, sensitive, and selective method for determination of chlorogenic acid in green coffee. Therefore, the objective of the present work was the development and validation of an analytical

This is an open-access article distributed under the terms of the Creative Commons Attribution-NonCommercial 4.0 International License (https://creativecommons.org/licenses/by-nc/4.0/), which permits unrestricted use, distribution, and reproduction in any medium for non-commercial purposes, provided the original author and source are credited, a link to the CC License is provided, and changes - if any - are indicated. 
method for determination of chlorogenic acid in green coffee. The method is required to have excellent sensitivity, i.e., low limit of detection (LOD) and limit of quantification (LOQ), so that low concentrations of chlorogenic acid can be determined.

\section{Experimental}

Chemicals and Reagents. The analytical standard of chlorogenic acid $(95 \%)$ was produced by Sigma Aldrich (Germany). The mobile phase was prepared using acetonitrile, water (HPLC grade), methanol, and phosphoric acid (85.5\%), all produced by Sigma Aldrich (Germany). One commercial product containing green coffee purchased from a local pharmacy and 4 samples of green coffee produced by "Rio Coffee" company from Skopje, Macedonia, were used in this investigation.

Instrumentation. Liquid chromatography analysis was performed on an Agilent 1260 Infinity Rapid Resolution Liquid Chromatography (RRLC) system equipped with a vacuum degasser (G1322A), a binary pump (G1312B), an auto sampler (G1329B), a thermostatted column compartment (G1316A), a UV/Vis diode array detector (G1316B), and ChemStation software. For separation and quantification of investigated chlorogenic acid, the following columns, Purospher STAR RP-18e $(30 \times 4 \mathrm{~mm} ; 3 \mu \mathrm{m})$, LiChrospher 60 RP-select B $(125 \times 4 \mathrm{~mm} ; 5 \mu \mathrm{m})$, and Poroshell 120 EC-C18 $(50 \mathrm{~mm} \times 3 \mathrm{~mm} ; 2.7 \mu \mathrm{m})$, were used. Ultrasonic bath "Elma" (D-7700 SINGEN/Htw., Germany) was applied for dissolution of a stock solution.

Preparation of Standard and Working Solution. Standard solution of chlorogenic acid was prepared by dissolving $0.0173 \mathrm{~g}$ of analytical standards in methanol in a $10-\mathrm{mL}$ volumetric flask. The prepared stock solution was degassed using an ultrasonic bath "Elma "for $15 \mathrm{~min}$. In order to test the linearity of the method, 6 working solutions with different concentration of chlorogenic acid were prepared by appropriate dilution of the standard solutions with $80 \%$ methanol. Preparation of these solutions was achieved with standard solution volumes of $75 \mu \mathrm{L}, 175 \mu \mathrm{L}, 350 \mu \mathrm{L}$, $525 \mu \mathrm{L}, 700 \mu \mathrm{L}$, and $875 \mu \mathrm{L}$ of chlorogenic acid in $10-\mathrm{mL}$ volumetric flasks. All solutions were stored in the dark in a refrigerator at a temperature of $4{ }^{\circ} \mathrm{C}$.

Sample Preparation. Five different samples marked with numbers $1,2,3,4$, and 5 were analyzed applying developed method. A mass of $0.25 \mathrm{~g}$ from each sample was measured in triplicate into a $50-\mathrm{mL}$ beaker. After that, to the beaker, different solvents were added in order to establish the extraction procedure that gives the best results. Three different extraction procedures for all samples were performed.

First extraction: $0.25 \mathrm{~g}$ sample and $25 \mathrm{~mL}$ distillated water were mixed into a $50-\mathrm{mL}$ beaker and then were heated and boiled for 5 min with continuous mixing.

Second extraction: $0.25 \mathrm{~g}$ sample and $25 \mathrm{~mL}$ distillated water were mixed into a $50-\mathrm{mL}$ beaker and then were ultrasonicated for 15 min with an ultrasonic bath.

Third extraction: $0.25 \mathrm{~g}$ sample and $25 \mathrm{~mL}$ methanol water were mixed into a $50-\mathrm{mL}$ beaker and then were ultrasonicated for $15 \mathrm{~min}$ with an ultrasonic bath.

After extraction, $1 \mathrm{~mL}$ from each extract was transferred in a $10-\mathrm{mL}$ volumetric flask and filled up to the mark with $80 \%$ methanol. Prior to RRLC analysis, these extracts were filtered through $0.45 \mu \mathrm{m}$ Iso-Disc PTFE syringe filters (Supelco, Sigma Aldrich, Germany). Finally, a volume of $5 \mu \mathrm{L}$ was injected into the column in triplicate.

RRLC Conditions. Preliminary studies for the development of the RRLC method for determination of chlorogenic acid involved 3 different analytical columns and a mobile phase with different compositions. Columns: Purospher STAR RP-18e $(30 \times 4 \mathrm{~mm} ; 3 \mu \mathrm{m})$, LiChrospher 60 RP-select B $(125 \times 4 \mathrm{~mm} ; 5 \mu \mathrm{m})$, and Poroshell 120 EC-C18 $(50 \times 3 \mathrm{~mm} ; 2.7 \mu \mathrm{m})$ were tested. Mobile phase consisted of acetonitrile-water, methanol-water, methanol- $0.5 \%$ formic acid in water, and methanol- $0.05 \%$ formic acid in water with different volume ratios were tested. The chromatographic analysis was performed using isocratic elution with a flow rate of $1 \mathrm{~mL} / \mathrm{min}$, and a volume of $5 \mu \mathrm{L}$ was injected into the chromatographic system, at room temperature. A wavelength of $325 \mathrm{~nm}$ was set up for UV detection. The retention time of chlorogenic acid under the abovementioned chromatographic conditions was $0.96 \mathrm{~min}$, which means that the time of the analyses was less than $1 \mathrm{~min}$. Chlorogenic acid in the samples was identified on the basis of the retention time, as well as by comparison between the UV spectrum of chlorogenic acid in the standard solution and the UV spectrum of the detected peak in the samples. Quantification was made with a freshly prepared standard curve of chlorogenic acid.

\section{Results and Discussion}

UV Spectrum of Chlorogenic Acid. The UV spectrum of chlorogenic acid recorded in acetonitrile-water with $1 \%$ phosphoric acid $(10: 90, v / v)$, with a flow rate of $1 \mathrm{~mL} / \mathrm{min}$ at $25^{\circ} \mathrm{C}$, is presented in Figure 1.

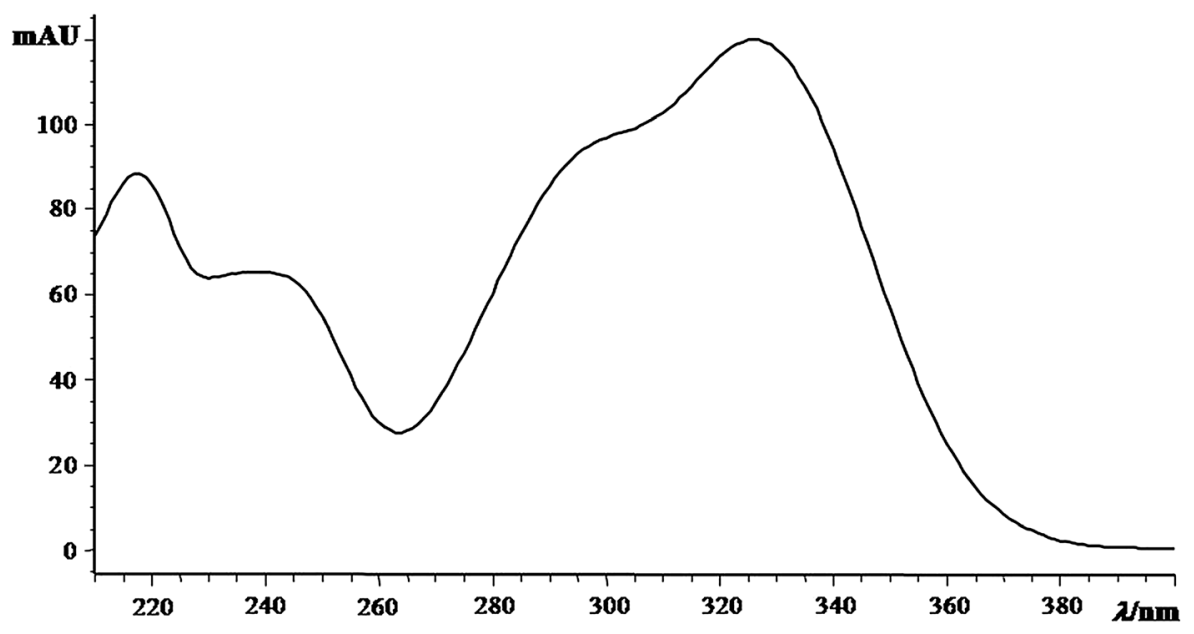

Figure 1. UV spectrum of chlorogenic acid in acetonitrile-water with $1 \%$ phosphoric acid $(10: 90, v / v)$, at a flow rate of $1 \mathrm{~mL} / \mathrm{min}$, with UV detection at $325 \mathrm{~nm}$, and at $25^{\circ} \mathrm{C}$ 
As it can be seen from Figure 1 in the UV spectrum of chlorogenic acid, there are 2 absorption maxima. First maximum, which is less intensive, appears at the $220-\mathrm{nm}$ wavelength, and the second one is located at the $325-\mathrm{nm}$ wavelength. Hence, the chromatographic process of determination of chlorogenic acid was followed at $325 \mathrm{~nm}$.

Method Development. As it was mentioned in the experimental, 3 different analytical columns and a mobile phase with different compositions were tested. The obtained results showed that the optimal conditions for qualitative and quantitative determination of chlorogenic acid in green coffee samples were achieved using the analytical column Poroshell 120 EC-C18 $(50 \times 3 \mathrm{~mm} ; 2.7 \mu \mathrm{m})$, isocratic elution with a mobile phase composed of acetonitrile-water with $1 \%$ phosphoric acid $(10: 90, v / v)$, a flow rate of $1 \mathrm{~mL} / \mathrm{min}$, UV detection at $325 \mathrm{~nm}$, and a temperature of $25^{\circ} \mathrm{C}$ (Figure 2).

From Figure 2, it can be seen that under the defined experimental conditions, the dead time of the column was $0.25 \mathrm{~min}$, while the retention time of investigated chlorogenic acid was $0.96 \mathrm{~min}$. The calculated retention factor value was 2.76, which is the optimal value for this parameter [20]. The columns Purospher STAR RP-18e $(30 \times 4 \mathrm{~mm} ; 3 \mu \mathrm{m})$ and LiChrospher 60 RP-select B $(125 \times 4 \mathrm{~mm} ; 5 \mu \mathrm{m})$ were not efficient enough for separation and quantification of chlorogenic acid in the presence of the other isomers in the coffee samples.

Method Validation. Validation of the method for determination of chlorogenic acid in green coffee was performed testing following parameters: linearity, specificity, selectivity, precision, accuracy, limit of detection (LOD), and limit of quantification (LOQ). Linearity is actually the ability of a method to obtain test results that are directly proportional to the analyte concentration within a given range. To evaluate linearity, a minimum of 5 concentration levels are required. In our investigation, six working solutions of chlorogenic acid in the investigated concentration region were tested by RRLC with ultraviolet detection (RRLC-UV) in order to set up the linearity of the developed method. A $5-\mu \mathrm{L}$ volume of each test solution was injected in triplicate. The plot of the peak area/height versus concentration of chlorogenic acid was found to be linear in the concentration region from 12.33 to $143.50 \mu \mathrm{g} / \mathrm{mL}$ (Table 1).

An acceptance criterion for linearity is that the value of coefficient of determination $\left(R^{2}\right)$ is not less than 0.99 [21]. In our work, the calculated values of $R^{2} \geq 0.998$ demonstrated that the developed method for determination of chlorogenic
Table 1. Linearity data for determination of chlorogenic acid

\begin{tabular}{lccc}
\hline Linearity range $(\mu \mathrm{g} / \mathrm{mL})$ & \multicolumn{2}{c}{ Regression equation } & $R^{2}$ \\
\hline $12.33-143.50$ & peak area & $y=4.3215 x+25.763$ & 0.9980 \\
& peak height & $y=0.7364 x+12.203$ & 0.9981 \\
\hline
\end{tabular}

acid was characterized by excellent linearity (Table 1). The specificity and selectivity of the developed method were estimated with the identification of peak of interest and the obtained values for purity index. The identification of analyte was performed by comparison of the retention time of analytical standard with the retention time of chlorogenic acid in the analyzed green coffee samples. Additionally, the identification was confirmed with overlapping the absorption spectrum of pure analytical standard and the absorption spectrum of chlorogenic acid in the analyzed samples. Thereby, the value of a match factor was taken into consideration. The value of this factor was greater than 999, which confirmed that the chromatographic peak originated from the same compound (Figure 3).

Precision is the measure of the degree of repeatability of an analytical method, and it is expressed as the relative standard deviation (RSD) for a significant number of samples. The RSD for the replicate of injections should not be greater than $1.5 \%$ [22]. In our study, the precision of the developed method was expressed as intra-day precision. In order to test precision, 10 successive injections of analytical standard with a mass concentration of $12.33 \mu \mathrm{g} / \mathrm{mL}$ were made.

The calculated RSD values using peak area, retention time and peak height are given in Table 2 .

These obtained RSD values demonstrated that the developed method for determination of chlorogenic acid is repeatable. Limit of detection (LOD) and limit of quantification (LOQ) values were determined in order to evaluate the sensitivity of the developed method. LOD is the lowest concentration of analyte in a sample that can be detected, while LOQ is defined as the lowest amount of analyte which can be reproducibly quantified under the defined experimental conditions. In order to determine LOD and LOQ, the solution was injected three times, and then the signal-to-noise ratio $(S / N)$ for each injection was determined. LOD was determined as the amount of analyte which produces an $S / N$ ratio of $3: 1$. LOQ was determined in the same manner but with $S / N=$ 10:1. The values of LOD and LOQ for chlorogenic acid using this method are shown in Table 2.

The accuracy of the method measures the agreement between the accepted reference value and the obtained value

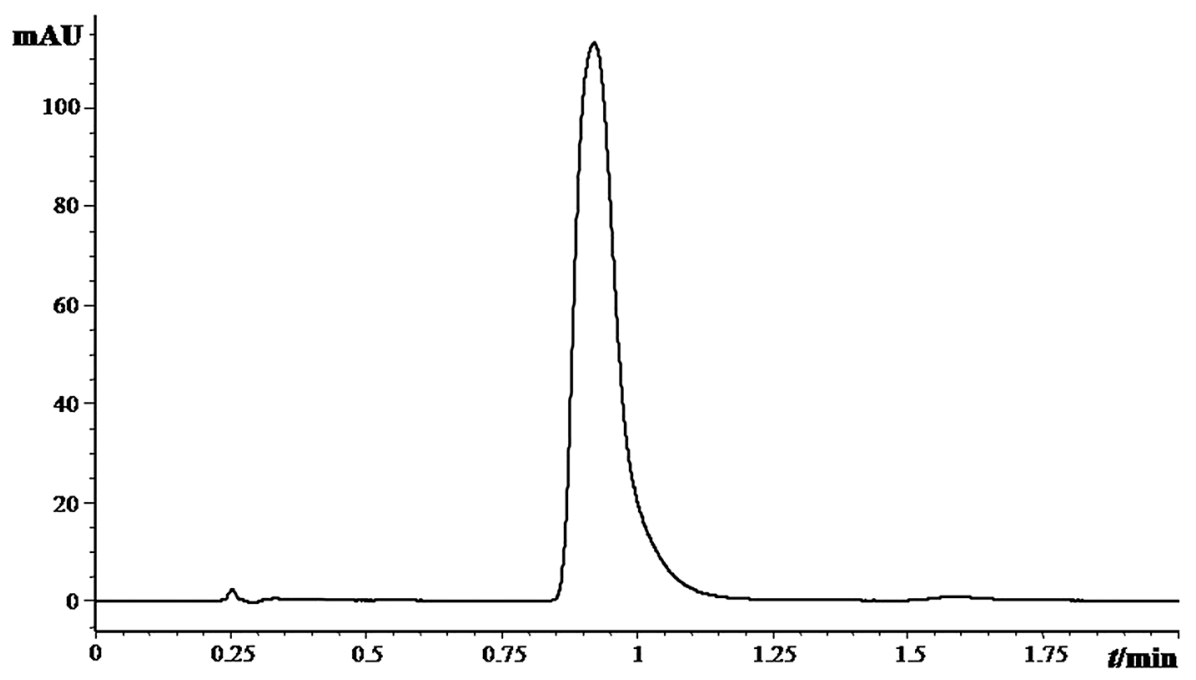

Figure 2. Chromatogram of analytical standard of chlorogenic acid obtained with a mobile phase consisting of acetonitrile and $1 \%$ phosphoric acid dissolved in water $(10: 90, v / v)$, at a flow rate of $1 \mathrm{~mL} / \mathrm{min}$ and a temperature of $25^{\circ} \mathrm{C}$ and with UV detection at $325 \mathrm{~nm}$ 


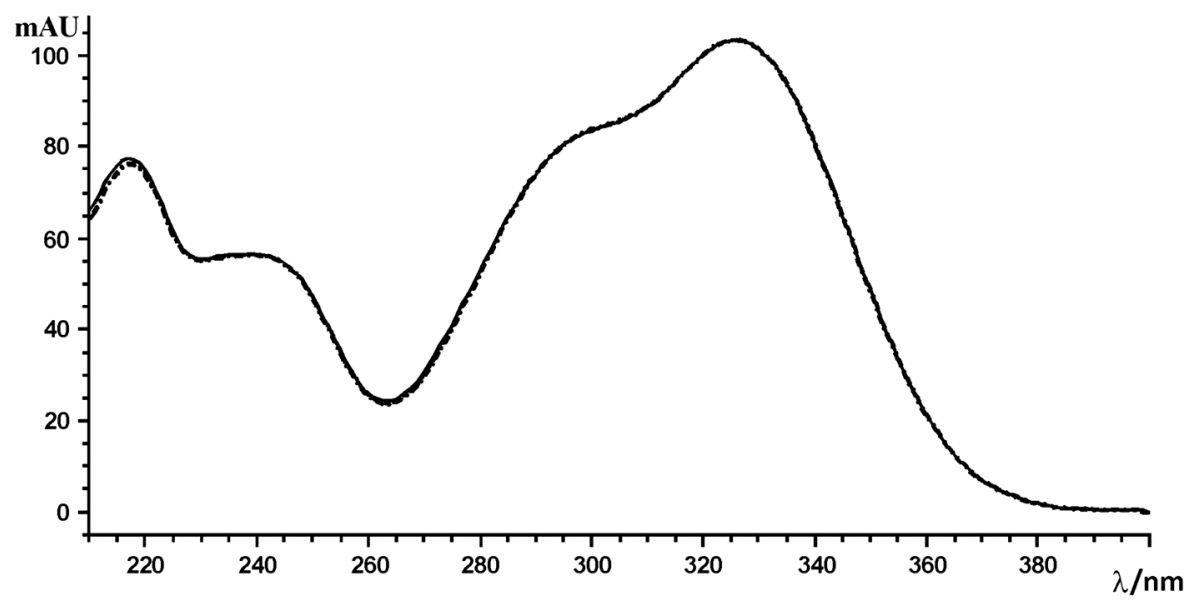

Figure 3. Overlapped UV spectra of chlorogenic acid in the standard solution and the sample, with the mobile phase acetonitrile-water with $1 \%$ phosphoric acid $(10: 90, v / v)$, at a flow rate of $1 \mathrm{~mL} / \mathrm{min}$, with $\mathrm{UV}$ detection at $325 \mathrm{~nm}$, and at $25^{\circ} \mathrm{C}$

Table 2. Intraday precision, LOD, and LOQ of the method

\begin{tabular}{lcccc}
\hline $\begin{array}{l}\text { RSD retention } \\
\text { time }(\%)\end{array}$ & $\begin{array}{c}\text { RSD peak } \\
\text { area }(\%)\end{array}$ & $\begin{array}{c}\text { RSD peak } \\
\text { height }(\%)\end{array}$ & $\begin{array}{c}\text { LOD } \\
(\mathrm{pg})\end{array}$ & $\begin{array}{r}\text { LOQ } \\
(\mathrm{pg})\end{array}$ \\
\hline 1.10 & 0.19 & 1.32 & 0.29 & 0.96 \\
\hline
\end{tabular}

Table 3. Recovery data of the developed method, $n=3$

\begin{tabular}{cccccc}
\hline & $\begin{array}{c}\text { Mass of } \\
\text { analyte }(\mathrm{ng})\end{array}$ & $\begin{array}{c}\text { Pure analyte } \\
\text { added (ng) }\end{array}$ & $\begin{array}{c}\text { Total analyte } \\
\text { found }(\mathrm{ng})( \pm \mathrm{SD})\end{array}$ & $\begin{array}{c}\text { Recovery } \\
(\%)\end{array}$ & $\begin{array}{c}\text { RSD } \\
(\%)\end{array}$ \\
\hline \multirow{3}{*}{ Sample 1 } & 109.16 & 82 & $200.28 \pm 0.76$ & 104.77 & 0.62 \\
& 109.16 & 164 & $263.04 \pm 0.31$ & 97.87 & 0.13 \\
& 109.16 & 246 & $378.86 \pm 0.25$ & 106.67 & 0.13 \\
\hline
\end{tabular}

Table 4. Mass and mass fraction of chlorogenic acid in the analyzed samples, $n=3$

\begin{tabular}{lccc}
\hline Sample & $m(\mathrm{ng}) \pm$ SD $($ volume of $5 \mu \mathrm{L})$ & RSD $(\%)$ & Mass fraction[\%] \\
\hline 1 & $109.16 \pm 0.33$ & 0.28 & 2.18 \\
2 & $146.51 \pm 0.35$ & 0.24 & 2.93 \\
3 & $158.86 \pm 0.10$ & 0.06 & 3.18 \\
4 & $154.65 \pm 0.38$ & 0.24 & 3.09 \\
5 & $169.47 \pm 1.14$ & 0.67 & 3.39 \\
\hline
\end{tabular}

using the method of standard addition [23]. Accuracy was measured as the percentage of analyte recovered after spiking the known amount of the analytical standard into a sample of green coffee which already contained a determined amount of chlorogenic acid. The obtained RSD values give an indication of the accuracy of the developed method. The mean recovery of the assay should be within $100 \pm 5 \%$ at each concentration over the studied range [24]. In order to determine the accuracy, 3 concentration levels were analyzed, i.e., 9 injections into the chromatographic system. A known amount of chlorogenic acid was spiked into sample 1 . The average recovery and RSD for each concentration level was calculated, and the obtained results are presented in Table 3.

As it can be seen from the data listed in Table 3, the calculated recovery values were ranged between 97.87 and $106.67 \%$. These results showed that the developed method had good recovery at the 3 studied concentration levels with RSD values lower than $1 \%$, i.e., it can be successfully employed for quantitative determination of chlorogenic acid in green coffee samples.

Analysis of Chlorogenic Acid in Green Coffee Samples. The applicability of the developed method was tested by the identification and quantitation of the chlorogenic acid in one commercial product containing green coffee and 4 samples of green coffee. Identification of the chlorogenic acid was based on retention time in comparison with the analytical standard, while the quantification was carried out using the external standard method. The concentration of chlorogenic acid was calculated using the peak area and the calibration curves obtained from the used standard solutions. The amount of chlorogenic acid was expressed as ng per $5 \mu \mathrm{L}$ of the sample. All samples were prepared according to the first extraction procedure explained in Sample Preparation. This way of

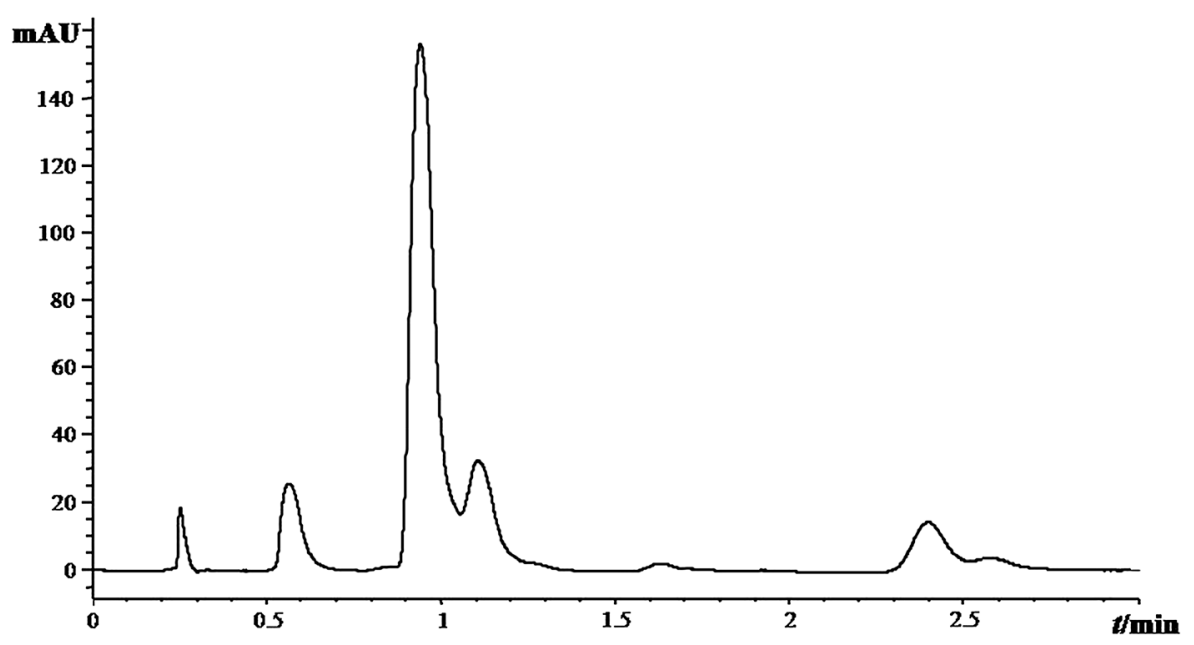

Figure 4. Chromatogram of sample 5, with the mobile phase acetonitrile-water with $1 \%$ phosphoric acid $(10: 90, v / v)$, at a flow rate of $1 \mathrm{~mL} / \mathrm{min}$, with UV detection at $325 \mathrm{~nm}$, and at $25^{\circ} \mathrm{C}$ 
extraction was chosen because it gave the best results for extraction of chlorogenic acid. In addition, chlorogenic acid was not successfully extracted using the second and third ways of extraction. The obtained average values for the determined amount of chlorogenic acid in the investigated samples are shown in Table 4. The chromatogram of the chlorogenic acid detected in sample 5 is presented in Figure 4.

The obtained results showed that the concentration of chlorogenic acid was similar for green coffee samples from 2 to 5 , while the concentration of chlorogenic acid was lower for the investigated commercial product containing green coffee. The RSD values were less than $1 \%$ for all investigated samples.

\section{Conclusion}

In this work, a simple, precise, accurate, and selective RRLC method with UV-DAD detection for determination of chlorogenic acid in green coffee was developed and validated. Separation was achieved on a Poroshell 120 EC-C18 (50 mm $\times 3 \mathrm{~mm} ; 2.7 \mu \mathrm{m}$ ) column with a mobile phase consisted of water with $1 \% \mathrm{H}_{3} \mathrm{PO}_{4}$ and acetonitrile $(90: 10, v / v)$. The great advantage of this method over those known from the literature is the composition of the mobile phase, i.e., a small amount of acetonitrile was used. Under the used experimental conditions, the retention time of chlorogenic acid was $0.94 \mathrm{~min}$. Hence, the analysis was completed in a shorter time compared to the previously published methods. Furthermore, a simple procedure for extraction of chlorogenic acid from the samples was used. The method was validated for linearity, LOD, LOQ, accuracy, and precision. The obtained results demonstrated that the developed method was characterized with linearity in a wide range, and it was accurate with a recovery between 97.87 and $106.67 \%$. This method was also precise, which was confirmed by the RSD values lower than $1 \%$. Low LOD and LOQ enable the detection and quantification of chlorogenic acid at a low concentration. All mentioned performances made this method suitable for routine analysis of chlorogenic acid in green coffee samples.

\section{References}

1. Ayelign, A.; Sabally, K. Am. J. Res. Commun., 2013, 1, 78.

2. Franca, A. S.; Mendonca, J. C. F.; Oliveira, S. D. Food Sci. Technol., 2005, 38, 709 .

3. Liu, H.; Shao, J.; Li, Q.; Li, Y.; Yan, H. M.; He, L. J. AOAC Int. 2012, 95, 1138.

4. Gebeyehu, B. T.; Bikila, S. L. Am. J. Appl. Chem., 2015, 3, 69.

5. Fuentes, E.; Palomo, I. Vascul. Pharmacol., 2014, 63, 155.

6. Belay, A.; Gholap, A. V. Afr. J. Pure and Appl. Chem., 2009, 3, 234.

7. Farah, A.; Paulis, T. D.; Moreira, D. P.; Trugo, L. C.; Martin, P. R. J. Agric. Food Chem., 2006, 54, 374.

8. Mills, C.; Oruna-Concha, M. J.; Mottram, D. S.; Spencer, J. P. E. Food Chem., 2013, 141, 3335.

9. Hecimovic, I.; Belscak-Cvitanovic, A.; Horzic, D.; Komes, D. Food Chem., 2011, 129, 991.

10. Lough, W. J.; Wainer, I. W. High Performance Liquid Chromatography, Fundamental Principles and Practice Blackie Academic \& Professional UK. Chapman \& Hall, Glasgow, 1996, p. 1-167.

11. Mullen, W.; Freeke, J.; Barattini, V. Fast analysis of Coffee Bean Extracts Using a Solid Core HPLC Column, University of Glasgow, UK, 2012, p. 1

12 Jeszka-Skowron, M.; Zgoła-Grześkowiak, A.; Grześkowiak, T. Eur. Food Res. Technol. 2015, 240, 19.

13. Craig, A. P.; Fields, C.; Liang, N.; Kitts, D.; Erickson, A. Talanta, 2016, 154, 481-485.

14. Rostagno, M.; Manchón, N.; D’Arrigo, M.; Guillamón, E.; Villares, A.; García-Lafuente, A. Anal. Chim. Acta., 2011, 685, 204.

15. Naczk, M.; Shahidi, F. J. Chromatogr. A, 2004, 1054, 95

16. Pyrzynska, K.; Sentkowska, A. Crit. Rev. Anal. Chem., 2015, 45, 41.

17. Robards, K. J. Chromatogr. A., 2003, 1000, 657.

18. Li, X.P.; Yu, J.; Luo, J.Y.; Li, H.S.; Han, F.J.; Chen, X.G.; Hu, Z.D.

Chem. Pharm. Bull., 2004, 52, 1251.

19. Pellati, F.; Benvenuti, S.; Melegari, M.; Lassegni, T. Phytochem. Anal., 2005, $16,77$.

20. Meyer, V. R. Practical High-Performance Liquid Chromatography 2nd Ed., John Wiley \& Sons. England, Chichester, 1994, p. 1-267.

21. Al-Rimawi, F.; Odeh, I. J. AOAC Int., 2015, 98, 1335.

22. Huber, L. Validation and Qualification in the Analytical Laboratories Interpharm Press, Buffalo Grove, IL, 1998, p. 107.

23. Skoog, D.A.; West, D.M.; Holler, F. J. Analytical chemistry $6^{\text {th }}$ Ed., Saunders College Publishing, 1994, p. 490-530.

24. Wegscheider, W. Accreditation and Quality Assurance in Analytical Chemistry, ed. Guenzler, H., Springer Verlag, Berlin, Germany, 1996, p. 1. 